\title{
Moral normativity as a factor motivating the success of a modern teacher
}

\author{
Yu.V. Paigunova ${ }^{1 *}$, N.Z. Appakova-Shogina ${ }^{2}$, and A.V. Gut ${ }^{3}$ \\ ${ }^{1}$ Volga Region GUFKSIT University, Kazan, Russia \\ 2 Volga Region GUFKSIT University, Kazan, Russia \\ 3 Volga Region GUFKSIT University, Kazan, Russia
}

\begin{abstract}
The article is devoted to the theoretical and empirical study of the relationship between the moral normativity of a professional teacher and the motivation for success. The article analyzes the concept of moral normativity (from the point of view of the proposed conventional approaches) as a predictor of the teacher's professional activity. In the context of the study of the influence of moral normativity on the success of professional activity, the authors turn to the phenomenon of "macchiavelism", which reflects the existence of a high correlation of the need to achieve goals with a low moral normativity of the individual.The empirical part of the study presents the results of the correlation analysis of the indicator of moral normativity with various indicators that determine the motivation for success, on a sample of 150 future teachers of physical culture and sports profile (graduates of the Volga State University of Physical Culture, Sports and Tourism, Kazan). The results obtained indicate the ambiguity of the relationship between moral normativity and motivation for success in the context of professional pedagogical activity.
\end{abstract}

\section{A problem statement}

The logical-analytical philosophical tradition of the XX century called for the need to introduce a strict methodology in the study of morality, and psychological science tried to link ethics and natural science knowledge, which was reflected in the formation of the concept of moral normativity [1]. At the same time, in the modern globalized world, permeated with postmodern philosophy, and marked by normative relativism, it is still difficult to give an unambiguous definition of moral normativity as a psychological phenomenon. Moreover, philosophers note that the very concept of "morality" already has such a significant amount of meanings and connotations that it is not possible to combine all its possible dimensions in a single concept, although this is required by ethics [1]. K. Alchurron and E. Bulygin in "Normative Systems" put forward the concept of a norm, which is neither absolute nor relative, strictly speaking. The article defends the position that according to the ideas of the authors of "Normative Systems", the idea of a normative relationship lies beyond logic and belongs to social regulation [2].

\footnotetext{
*Corresponding author: prof-ped.gpa@mail.ru
} 
The question of the definition of moral normativity is now relevant in its applied meaning, in particular, when analyzing this concept in relation to other personality formations - values, attitudes, motives of activity, including professional activity.

\subsection{The objective of the work}

The aim of the work is to study theoretically and empirically the relationship of moral normativity with success motivation of professional teacher.

\section{Results of the research}

It is generally accepted that the moral normativity of a subject is a case of applying moral norms, that is, a system of behavioral regulatives in certain situations. But the main question in relation to moral normativity is the question of the justification of these norms. That is, from the point of view of the subject, the exclusive property of moral normativity should be the justification of moral norms, and the adequacy of their application in the context of social relations. The phenomenon of moral normativity in general philosophical terms is a way of modeling moral actions implemented within the framework of the proposed system of rules. Various classifications of moral norms can be distinguished (Table 1).

Table 1. Classification of moral norms on various grounds.

\begin{tabular}{|l|l|}
\hline \multicolumn{1}{|c|}{ Basis for classification } & \multicolumn{1}{c|}{ Classification } \\
\hline By constancy & $\begin{array}{l}\text { Actions are Temporary } \\
\text { Actions are Permanent }\end{array}$ \\
\hline By the nature of the control & $\begin{array}{l}\text { Prohibiting } \\
\text { Prescribing }\end{array}$ \\
\hline \multirow{2}{*}{ According to the degree of control } & $\begin{array}{l}\text { Categorical } \\
\text { Conventional } \\
\text { Factual }\end{array}$ \\
\hline
\end{tabular}

The comparative analysis of various models of moral normativity and the identification of its specific characteristics, as well as the boundaries and conditions of action, are designed to expand the analytical potential of psychological science. The study of moral normativity and the formulation of its model can significantly develop the modern analysis of moral discourse. Morality appears as a specific system of regulation that is effective from the point of view of the coherence of the action of all its elements, as well as the unity of the results - the ordering of social ties. Morality acts as a fairly rigid system-both in terms of duties and obligations, and in terms of values. The question of the nature of morality, or rather the features and sources of its action in the human community, is transformed in principle into the question of the nature and sources of moral norms. The study of normativity was conducted from various points of view and was often combined (or identified) with the consideration of moral normativity. The existing traditional methods of analyzing morality are limited due to the fact that they are initially addressed to the sphere that constitutes morality in the classical sense. The most frequently encountered approach to the study of moral normativity is the consideration of the ethical sphere through the category of the due, representing the value-normative ideal, transcendent to the life world of existence. Also popular is the approach associated with the dilemma of autonomy and heteronomy of the moral consciousness of the subject. Within the framework of this approach, moral normativity is considered from the point of view of the discourse "social and individual in man". Moral discourse becomes a heterogeneous, multi-level structure that exists in the form of removing the conflict between the social and the 
individual - a kind of system of checks and balances in society. The philosopher I.D. Nevvazhay distinguishes two approaches to the understanding of normativity-intentional and responsive, and intentional normativity appears as the creation of interpretive structures by the intellect, the active rational creation of meanings, and responsive normativity does not seek interpretation, although it participates in its creation by finding an adequate expression, for example, in language, terminology, artistic experience. Thus, there are two cultures in society - a culture of rules and a culture of expression. In the sphere of morality, the culture of rules is based on the principle of pleasure, and the culture of expression on the principle of duty [3].

Moral discourse does not have a given external normativity, but it produces it itself, including new forms and formats of action. The above-mentioned conditions and circumstances of the unfolding of moral discourse result, as a result, in the phenomenon of moral normativity, which in relation to them acts as the objective facticity of the action of the subject and the social norm, which we are forced to recognize when talking about morality. That is, within the framework of the current reasoning, it can be stated that the reduction of the sphere of moral normativity to its fundamental conditions is not final and urgently requires further clarification.

The formation of moral normativity is mediated by the experience of the individual and his activities, during which moral concepts and moral feelings are formed. As an example, we will refer to several modern studies on this topic. In particular, the study of Alimov A.A. and Smotrova T.N. is devoted to the identification of the relationship between moral normativity and the tendency to experience feelings of guilt and shame in representatives of different ethnic groups [4]. According to ethnopsychologists, moral normativity is determined by the national-cultural factor, and each ethnic group in the course of its social development develops fundamental moral, spiritual and cultural principles that determine the way of life, worldview and appropriate behavior, which, being specific, are interfaced with universal values. According to Belykh T.V., moral normativity is a determinant of personal adaptive potential [5]. The same point of view is shared by A.G. Maklakov and S.V. Chermyanin, who included the scale of moral normativity in their methodology for assessing the adaptive potential of the individual [6].

The problem of moral normativity is mainly presented in the foreign research literature, while the domestic ethical school is only discovering this problem. There are several areas that unite the research of moral normativity in science (Table 2).

Among these theoretical directions, the greatest opportunities for empirical research in individual and social psychology is moral constructivism, where the basis of normativity is a system of social interactions that have already developed in practice, which are fixed in the subject in the form of moral judgments. Thus, moral normativity is the ability of an individual to understand and accept the norms and rules of mutual behavior established in society [14].

Turning to the problem of the relationship between moral normativity and motivation for success, I would like to draw attention to another psychological phenomenon, the analysis of which is able to shed light on the essential mechanisms of this relationship. In our opinion, in psychological terms, the phenomenon of moral normativity is inextricably linked with the phenomenon that has received the name «Machiavellianism» in modern literature. 
Table 2. The studies of moral normativity in modern science.

\begin{tabular}{|c|c|c|}
\hline & $\begin{array}{l}\text { Direction (school) of } \\
\text { research on moral } \\
\text { normativity }\end{array}$ & $\begin{array}{l}\text { Main ideas/Main authors-representatives of the } \\
\text { school-direction }\end{array}$ \\
\hline 1 & $\begin{array}{l}\text { General Theoretical } \\
\text { Research }\end{array}$ & $\begin{array}{l}\text { Offers a philosophical, legal and ethical review of the } \\
\text { idea of norm and normativity in modern humanitarian } \\
\text { thought / Shelley Kagan (1998) [7] }\end{array}$ \\
\hline 2 & $\begin{array}{l}\text { The analysis of the } \\
\text { sources of moral } \\
\text { normativity and basic } \\
\text { approaches }\end{array}$ & $\begin{array}{l}\text { Reveals the main approaches to moral normativity: } \\
\text { rationalism, constructivism, voluntarism, realism, and } \\
\text { moral autonomy / Kristin Korsgaard (1992) [8] }\end{array}$ \\
\hline 3 & $\begin{array}{l}\text { The concept of rational } \\
\text { moral normativity }\end{array}$ & $\begin{array}{l}\text { The study of moral normativity through the prism of } \\
\text { rationalistic theory, which implies the use of the moral } \\
\text { subject in their actions and their assessment of the } \\
\text { criterion of value and utility, reasonable cooperation of } \\
\text { free individuals / J. Rawls, David Gauthier (1986) [9] }\end{array}$ \\
\hline 4 & $\begin{array}{l}\text { Communicative } \\
\text { foundations of moral } \\
\text { normativity }\end{array}$ & $\begin{array}{l}\text { A concept based on the principles of formal rationality, } \\
\text { communicative action, and substantive justification of } \\
\text { moral judgments / Yu. Habermas, Logi Gunnrason } \\
(2007)[10]\end{array}$ \\
\hline 5 & $\begin{array}{l}\text { Materialistic vision of } \\
\text { morality and moral } \\
\text { norms }\end{array}$ & $\begin{array}{l}\text { The concept of the rootedness of the subject's ability to } \\
\text { make moral judgments in its nature, more precisely, the } \\
\text { objective structure of human consciousness and the } \\
\text { principles of its work, thereby supporting the realism of } \\
\text { moral normativity / Mark Hauser (2007) [11] }\end{array}$ \\
\hline 6 & Moral constructivism & $\begin{array}{l}\text { Evaluation of various aspects of moral normativity. A } \\
\text { constructivist approach to moral discourse, according to } \\
\text { which the ethics of norms arises within the framework of } \\
\text { the existing cognitive, social and psychological } \\
\text { characteristics of an individual's behavior } \\
\text { / James Sterba (1989) [12]; Russ Schafer-Landau (2009) } \\
\text { [13] }\end{array}$ \\
\hline
\end{tabular}

The introduction of the concept of «Machiavellianism» into scientific psychological circulation belongs to foreign researchers. It was American psychologists who turned to the most famous political treatise of the Renaissance - «The Sovereign» by Niccolo Machiavelli, which significantly influenced not only the political, but also the philosophical thought of subsequent eras, on the basis of the content analysis of the work, created a psychological questionnaire, later called the «Mac Scale». Machiavelli's treatise, devoted to the analysis of the absolutization of power and the ways to achieve this power, has become an interesting tool for social psychology and personality psychology. Machiavellianism, in psychological interpretation, began to define the tendency to manipulate other people in interpersonal relationships. "Machiavellianism is usually defined as a person's tendency in interpersonal situations to manipulate others in subtle, or nonphysically aggressive ways, such as flattery, deception, bribery, or intimidation». [15] Researchers tend to view macchiavelism as a quantitative characteristic, believing that all people are capable of manipulative behavior, but to varying degrees. The immediate creators of the Mac-scale are R. Christie and F. Geis, recognizing the fact that macchiavelism can be considered in a quantitative aspect, also proposed a multidimensional measurement of this psychological syndrome, highlighting its cognitive, motivational and behavioral characteristics [16]. The main psychological principle on which the use of manipulative behavior by a person is based is the principle - «the end justifies the means», a phrase attributed to the authorship of 
Niccolo Machiavelli (Latin: Finis sanctificat media), although perhaps not quite true, because similar ideas belonged to other theologians and thinkers of this era-Ignatius Loyola, Antonio Escobar y Mendoza, Thomas Hobbes, Herman Buzenbaum [17].

As the results of empirical studies of foreign scientists have shown, high scores on the Mac scale positively correlate with externality, suspicion, hostility, but do not correlate with intelligence, rational attitudes and the level of anxiety [13]. It is acceptable to assume that macchiavelism should show a high correlation with the need to achieve goals and a low one with the moral normativity of the individual. Machiavellianism is aimed at achieving the pragmatic goals of the individual, and is a promiscuity in relation to the choice of means to achieve them. The English philosopher Thomas Hobbes categorically formulated this idea: «Since it is useless for someone who is denied the right to use the necessary means to strive for the goal, it follows that since everyone has the right to self-preservation, everyone has the right to use all means and perform any act without which he is not able to preserve himself» [18]. In our research, analyzing the motivation for success in the context of moral normativity, we set out to test this hypothesis, using the concepts of means, goals, results, to learn the patterns of relationships between motivation for success and aspects of their regulation represented in the public consciousness and moral norms. It should be noted that the tradition of applying a normative approach to the study of personality orientation is characteristic of Russian psychology, which has always been dominated by views on the crucial importance of social relations and conditions for the development of the motivational sphere of a person's personality. In particular, S. L. Rubinstein noted that the motives of a person are most determined by social tasks [19]. Representatives of the cultural and historical psychological school - A.N. Leontiev, A.R. Luria, L.S. Vygotsky postulated that social relations and conditions carry the motives of activity and the root causes of human activity are related to his life in society, his involvement in social relations $[20]$.

The correlation analysis of the indicator of moral normativity with various indicators that determine the motivation for success in a sample of 170 future teachers of physical culture and sports profile revealed a number of significant relationships (Table 3).

Table 3. Correlation values of moral normativity indicators with indicators of success motivation (values with a confidence level of 0.05 are shown).

\begin{tabular}{|l|c|}
\hline \multicolumn{1}{|c|}{ Indicators of motivation to success } & Lowmoral normativity \\
\hline Motive for success & 0.20 \\
\hline Avoiding Failure & -0.23 \\
\hline Self-interest & 0.20 \\
\hline Self-efficacy in subject of activity & 0.20 \\
\hline Self-efficacy in communication & 0.16 \\
\hline
\end{tabular}

The found correlations allow us to see the internal mechanisms of the role of moral normativity in the specifics of motivation for success. It is established that low moral normativity determines a higher motivation for success, lack of avoidance of failures, high self-confidence, self-efficacy. The results obtained indicate the ambiguity of the relationship between moral normativity and motivation for success.

In society, man finds not only the external conditions to which he must adapt his activities, but the social conditions themselves already contain the motives and goals, the means and methods of activity. Any activity contains indications of normative motives that should become dominant for the person involved in it. Experts distinguish several vectors 
of normative motivation in the activity. One of them is the motive of social significance and demand for the results of activities. This motive is also meaningfully associated with the normative motive of the obligation to obtain exactly the results that are set by social tasks, with the help of normative means of activity and in a normative way. Thus, for public activity (which, first of all, includes labor, professional activity), the most important thing is to obtain results that correspond to the specified norms and the use of non-normative means and methods of activity [21,22].

In opposition to this thesis, there is currently and is becoming increasingly widespread the position that the activity of the individual must first of all meet the demand for personal development, self-realization, self-improvement and self-affirmation of the person, and the purpose of the activity is not reduced to the production of socially useful results [5]. These are the concepts of eudaemonism, hedonism, utilitarianism, reasonable egoism, which obey the concept of consequentialism, the criterion of moral evaluation is the result (consequent) of behavior $[23,24,25]$.

\section{Conclusions}

The identification of two groups of motives naturally raises the question of their correlation in the activities of a professional, especially in relation to the field of motivation for success. In the case of the predominance of consequential motives, an attitude to activity can be formed as a means of achieving only one's own goals, achieving individualistic and egoistic results, without relying on moral norms.

The motives of the social purpose of the results of professional activity set the boundaries, including ethical and moral, within which the realization of the aspirations of the individual is allowed, but may limit its ability to achieve success. In our opinion, in approaches to the problem of the relationship between moral normativity and motivation for success, the most important thing is to find a way to harmonize the two groups of normative motives that allow the individual, without violating the principle of social normativity of activity, at the same time, to freely choose the means, methods and techniques for achieving success.

\section{References}

1. D.A. Gusev, Genesis of structures of moral normativity, Almanac (2012)

2. K.E. Alchurron, E.V. Bulygin, Normativnyesistemy, Russian Yearbook of the theory of law, 3, (2010)

3. I.D., Nevvazhay, Norm, communication, creativity, 215 (2018)

4. A.A. Alimov, T.N. Smotrova, The relationship of moral normativity with indicators of guilt and shame in representatives of different ethnic groups, Personality, family and society: questions of pedagogy and psychology, 9-10, 56 (2015)

5. T.V. Belykh, Moral normativity of behavior in the structure of integral individuality of modern student youth, Izv. Sarat. un-ta Ser. Philosophy. Psychology. Pedagogy, 2 (2014)

6. A.G. Maklakov, Multilevel personal questionnaire "Adaptivity", 164-174 (1994)

7. Kagan, Shelley. Regulatory ethics, Westview Press (1998)

8. K. Korsgaard, Sources of normativity, Cambridge University Press (1992)

9. D. Gauthier, Moral by agreement, Clarendon Press. Oxford (1986)

10. L. Gunnarsson, It Makes Moral Sense, Cambridge University Press (2007) 
11. Mark D. Hauser, Moral Minds, Harper Collins (2007)

12. Contemporary Ethics: selected readings (1989)

13. Oxford Studies in Metaethics (2009)

14. I.Y. Fomichev, Modes of moral normativity in management, 230 (1999)

15. V.V. Znakov, Machiavellism: the psychological property of the individual and the methodology of his research, Psychological Journal, 21(5) (2000)

16. Studies in Machiavellianism (1970)

17. B.G. Meshcheryakov, A.V. Nekrasova, Machiavellism, lies and truth in everyday life, Electronic version: URL:http://www.courier.com.ru/homo/ho0605mescheryakov.htm (2005)

18. Th. Hobbes, Philosophical foundations of the doctrine of the citizen, 304 (2003)

19. S.L. Rubinstein, Fundamentals of general psychology, 200 (2002)

20. A.N. Zhdan, L.S. Vygotsky, The scientific schools of the Moscow University, Unity in diversity, 3(1), 29-34 (2007)

21. A.A. Oboznov, Orientation of the professional personality: a normative approach, 120 (2014)

22. Craig Vansandt, Jon M. Shepard, An Examination of the Relationship Between Ethical Work Climate and Moral Awareness, Journal of Business Ethics, 68(4), 409-432 (2006)

23. S. Darwall, (ed.), Consequentialism, 200 (2002)

24. T. Hondrich, Consequentialism, the Moralities of Concern, and Selfishness, 120 (2009)

25. Douglas W. Portmore, Commonsense Consequentialism: Where in Morality Meets Rationality, 235 (2009) 